\title{
PERAN DUKUNGAN ORGANISASI DAN MODAL PSIKOLOGIS TERHADAP PSYCHOLOGICAL OWNERSHIP
}

\author{
Vina Krisanti ${ }^{1}$, Rostiana ${ }^{2}$, dan Daniel Lie ${ }^{3}$ \\ Fakultas Psikologi, Universitas Tarumanagara Jakarta \\ Email: vina.krisanti@gmail.com \\ Fakultas Psikologi, Universitas Tarumanagara Jakarta \\ Email: dutaindah03@yahoo.com \\ Fakultas Psikologi, Universitas Tarumanagara Jakarta \\ Email: danielsugianto@gmail.com
}

\begin{abstract}
This research is conducted to find the role of perceived organizational support and psychological capital to psychological ownership of the employees of PT ABC. Perceived organizational support as an independent variable has three dimensions which consist of fairness, supervisor support, and organizational reward. Psychological capital as an independent variable has four dimensions which consist of self-efficacy, hope, optimism, and resilience. As a dependent variable, psychological ownership is a unidimensional psychological construct. The participants of this research are employees of $P T A B C$ which is a clothing retail company ( $n=66)$. Research method used is non-experimental and data is processed using linear regression analysis method. The result of the research shows that perceived organizational support and psychological capital have $34 \%$ effect on psychological ownership with $F=16.246, p<0.05$. This research shows that psychological capital has more impact than perceived organizational support. From perceived organizational support variable, the dimension that has the most significant role to psychological ownership is organizational reward and from psychological capital variable, the dimension that has the most significant role to psychological ownership is resilience. Among these two free variables, psychological capital has the most significant role on psychological ownership.
\end{abstract}

Keywords: perceived organizational support, psychological capital, psychological ownership

\section{PENDAHULUAN}

Perasaan memiliki ternyata berperan penting dalam mengelola sebuah organisasi. Asumsi di balik gagasan ini ialah karyawan seharusnya memiliki perasaan akan memiliki (sense of ownership) sehingga karyawan akan memberikan energi dan usaha yang lebih terhadap perusahaan (Jafri, 2015). Pierce, Rubenfeld, dan Morgan (dalam Brown, Pierce, \& Crossley, 2014) menyarankan bahwa kepemilikan memanifestasikan dirinya sebagai fenomena hukum, dan juga disadari bahwa kepemilikan sebagai sebuah keadaan psikologis yang penting. Psychological ownership menurut Pierce et al. (2001) diartikan sebagai suatu keadaan di mana seseorang merasa bahwa suatu benda atau target adalah sebagai bagian dari diri mereka. Seseorang yang mempunyai rasa memiliki terhadap sesuatu hal akan mendapatkan kepuasan tersendiri atas hal yang dimilikinya. Olckers dan Plessis (2012) juga menambahkan bahwa orang akan lebih peduli dan menjaga miliknya sendiri. Didukung oleh pemikiran Belk (1988) dan Furby (1978) seseorang yang merasakan kepemilikan atas sebuah obyek akan mengembangkan rasa tanggung jawab untuk menjaga, melindungi, mempertahankan, dan mengembangkan apa yang menjadi miliknya tersebut.

PT. ABC yang saat ini bergerak di bidang retail tampak memiliki permasalahan perilaku kerja di dalam perusahaan. Berdasarkan hasil wawancara dengan Senior General Manager Human Capital and General Affair, saat ini perasaan memiliki dan rasa tanggung jawab nampak kurang terlihat dalam PT. ABC. Karyawan nampak kurang peduli, hal ini ditandai dengan kurangnya 
rasa kepedulian terhadap lingkungan kerja dan aset kerja yang terlihat dari hasil observasi peneliti selama penelitian ini berlangsung dari awal bulan Maret tahun 2016 sampai dengan sekarang. Karyawan dinilai kurang peduli dengan hasil akhir pekerjaannya, menurutnya karyawan memang sudah bekerja benar tetapi hasil yang diberikan baru sebatas yang diminta saja dan masih dibawah target (SFN, September 2016).

Berdasarkan teori psychological ownership yang dikemukakan oleh Pierce et al. (2001) dan perilaku karyawan di PT. ABC, menunjukkan bahwa adanya masalah perilaku karyawan yang ditampilkan seperti kurangnya perasaan memiliki, tanggung jawab, kepedulian dan kedekatan terhadap perusahaan. Masalah yang terkait dengan hal kepemilikan, tanggung jawab dan kepedulian apabila dikaitkan di dalam bidang psikologi industri dan organisasi dikenal sebagai psychological ownership.

Otken (2015) mengemukakan bahwa ada faktor eksternal dan faktor internal yang mampu memprediksi psychological ownership. Salah satu faktor eksternal yang dapat memengaruhi rasa kepemilikan karyawan adalah perlakuan yang diterima dari perusahaan. Hal ini telah diteliti oleh Otken (2015) yang menjelaskan bahwa Perceived Organizational Support (POS) atau dalam bahasa Indonesia diartikan sebagai dukungan organisasi yang dalam penelitiannya menjelaskan bahwa dukungan organisasi berpengaruh positif terhadap rasa kepemilikan karyawan.

Namun dari hasil penelitian yang dilakukan oleh Otken (2015) hanya dilakukan penelitian terhadap dua faktor dari tiga faktor dukungan organisasi yang ada. Kedua dimensi tersebut adalah "work-related support" dan "emotional support". Dari hasil penelitian menunjukkan variabel dukungan organisasi dan psychological ownership memiliki hubungan positif, apabila dilihat secara utuh pengaruhnya signifikan. Dilihat dari kedua dimensinya juga menunjukkan adanya hubungan yang positif antara dimensi "work-related support" dan dimensi "emotional support" terhadap psychological ownership, hanya masing-masing dimensi menghasilkan hubungan yang berbeda. Dimensi "emotional support" dengan psychological ownership memiliki hubungan yang kuat $(\mathrm{r}=.548 ; \mathrm{p}=.000)$ sedangkan dimensi "work-related support" dengan psychological ownership memiliki hubungan yang lemah $(r=.227 ; p=.000)$.

Perasaan memiliki akan berkembang pada saat individu memiliki fair justice perception di dalam pikiran mereka. Jadi, menurut Chi dan Han (dalam Ahmed, 2014) ada hubungan positif antara organizational justice perceptions dan psychological ownership. Hal ini bertentangan dengan penelitian yang dilakukan oleh Otken (2015) yang menyebutkan bahwa fairnes salah satu dimensi dukungan organisasi dikeluarkan dari penelitiannya dikarenakan memiliki faktor yang rendah terhadap psychological ownership.

Oleh karena dari hasil penelitian Otken (2015) nampak belum cukup kuat hasil yang ditampilkan, maka penelitian ini ingin menguji kembali hubungan antara kedua variabel tersebut. Selanjutnya, peneliti juga ingin melihat apakah seluruh dimensi dari dukungan organisasi berkaitan erat dengan psychological ownership serta memiliki peran terhadap psychological ownership.

Selain melihat dari faktor eksternal, peneliti juga ingin melihat faktor internal yang dapat meningkatkan psychological ownership karyawan terhadap perusahaan. Melihat kondisi perusahaan saat ini, sepertinya perusahaan membutuhkan karyawan yang memiliki rasa percaya diri dan optimis terhadap kondisi perusahaan di masa yang akan datang. Aspek-aspek tersebut 
ternyata tercakup dalam konsep yang disebut psychological capital (modal psikologis). Luthans (dalam Simon \& Buitendach, 2013) menjelaskan modal psikologis adalah konsep inti dalam literatur POB (Positive Organizational Behavior). POB didefinisikan sebagai pembelajaran dan aplikasi dari kekuatan positif sumber daya manusia dan sumber kapasitas psikologis yang dapat diukur, dikembangkan dan secara efektif mengatur peningkatan performa dalam tempat kerja sekarang ini.

Modal psikologis terdiri dari empat dimensi yaitu hope, optimism, resilience dan self-efficacy. Salah satu dimensinya yaitu hope berperan dalam memotivasi karyawan secara intrinsik dan menciptakan rasa keterlibatan dan keikutsertaan karyawan terhadap perusahaan, yang nantinya akan mengarahkan karyawan kepada rasa kepemilikan (sense of ownership) terhadap perusahaan (Arshad \& Abbasi, 2014).

Karyawan yang memiliki self-efficacy kuat menurut Gao (2000) akan lebih sukses dengan kemampuan dan usaha mereka sendiri, dan juga akan cenderung gagal karena kekurangan mereka dalam berusaha. Dalam waktu yang sama apabila self-efficacy karyawan kuat maka motivasi untuk beraksi menjadi lebih kuat juga. Dari hasil penelitian yang dilakukan oleh Min, $\mathrm{Hu}$, Zhang dan Li (2015) bahwa self-efficacy memiliki efek yang positif terhadap psychological ownership. Self-efficacy menciptakan psychological ownership yang dapat meningkatkan performa (Gong, Huang, \& Farh, 2009).

Oleh karena peran yang terbukti baru bersifat parsial baik dari modal psikologis maupun dukungan organisasi, maka peneliti tertarik untuk mengetahui lebih lanjut peran modal psikologis terhadap psychological ownership di PT. ABC. Peneliti tertarik untuk mengetahui lebih lanjut mengenai seberapa besar peran dukungan organisasi terhadap psychological ownership serta melihat seberapa besar peran modal psikologis terhadap psychological ownership. Adapun peneliti juga ingin melihat peran hubungan dukungan organisasi dan modal psikologis terhadap psychological ownership.

\section{METODE PENELITIAN}

Gambaran partisipan penelitian ini secara umum sebagai berikut, dari 66 partisipan, 38 orang $(57.6 \%)$ berjenis kelamin laki-laki, 28 orang $(42.4 \%)$ berjenis kelamin perempuan. 38 orang $(57.6 \%)$ memiliki pendidikan terakhir SMA/SMK, 47 orang $(71.2 \%)$ berada di level staf, 44 orang $(66.7 \%)$ memiliki masa kerja $1-5$ tahun, dan 47 orang $(71.2 \%)$ sudah menikah.

Penelitian ini merupakan penelitian kuantitatif dengan bentuk non-eksperimental. Teknik sampling yang digunakan adalah total sampling, dikarenakan seluruh karyawan di PT. ABC menjadi partisipan dan pengolahan datanya melalui program Statistical Product and Service Solutions (SPSS) 15. Desain penelitian yang digunakan adalah metode penelitian regression untuk melihat peran dukungan perusahaan dan modal psikologis terhadap psychological ownership. Berdasarkan rumusan tersebut, maka penelitian ini terdiri dari tiga variabel. Ketiga variabel penelitian yang digunakan adalah psychological ownership, dukungan perusahaan dan modal psikologis.

Pada penelitian ini, terdapat tiga skala untuk mengukur masing-masing variabel yaitu (i) psychological ownership, (ii) persepsi dukungan organisasi, dan (iii) modal psikologis. Semua butir yang terdapat di kuesioner dinyatakan dalam bahasa Indonesia. 


\section{Skala Psychological Ownership}

Menggunakan alat ukur yang dikembangkan oleh Pierce dan Dyne (2004) \& tahun 2014 alat ukur psychological ownership dikembangkan lagi oleh Brown, Pierce, dan Crossley menjadi enam butir dan sudah divalidasi oleh Van Dyne dan Pierce (2004). Alat ukur inilah yang digunakan pada penelitian ini. Contoh butir alat ukur psychological ownership seperti "Saya merasakan bahwa pekerjaan ini adalah MILIK SAYA", "Saya merasakan tingkat kepemilikan yang sangat tinggi untuk pekerjaan ini."

Skala respon yang digunakan pada alat ukur ini adalah Skala Likert dengan penjelasan sebagai berikut, 1 = Sangat tidak setuju; 2 = Tidak setuju; 3 = Agak tidak setuju; 4 = Antara setuju dan tidak setuju; $5=$ Agak setuju; $6=$ Setuju; $7=$ Sangat setuju. Adapun penjelasan pengukuran tiap dimensi akan dijelaskan pada alinea berikut.

Skor tinggi yang diperoleh partisipan dalam psychological ownership menunjukkan bahwa partisipan merasakan kepemilikan yang kuat terhadap pekerjaannya dan memandang pekerjaannya sebagai bagian dari dirinya. Alat ukur ini terdiri atas enam butir pernyataan dan dari pengujian reliabilitas dengan menggunakan internal consistency, nilai Alpha Cronbach yang diperoleh untuk alat ukur ini sebesar 0,781 dan tidak ada butir yang digugurkan setelah analisa pengolahan data.

\section{Skala Dukungan Organisasi}

Alat ukur yang digunakan untuk meneliti persepsi dukungan organisasi adalah Perceived Organizational Support Scale, alat ukur ini terdiri dari tiga dimensi yaitu dimensi keadilan, dukungan atasan, dan penghargaan organisasi \& kondisi pekerjaan. Alat ukur ini sudah diadaptasikan di Indonesia dan dikembangkan oleh Bagian Riset dan Pengukuran Fakultas Psikologi Universitas Tarumanagara pada tahun 2013. Skala respon yang digunakan pada alat ukur ini adalah Skala Likert dengan penjelasan sebagai berikut, $1=$ Sangat tidak sesuai; $2=$ Tidak sesuai; 3 = Ragu-ragu; 4 = Sesuai; 5 = Sangat Sesuai.

Skor tinggi yang diperoleh partisipan dalam dimensi keadilan menunjukkan bahwa partisipan semakin merasa perusahaan berlaku adil terhadap diri partisipan. Dimensi ini terdiri atas 12 butir pernyataan dan setelah dilakukan hasil uji analisis butir, ada 2 butir yang gugur karena nilai $r$ (Corrected item to total correlation) dibawah 0,2 yaitu butir nomor 4 dan 5. Oleh karena itu dimensi keadilan menjadi berjumlah 10 butir. Nilai Alpha Cronbach yang diperoleh untuk dimensi keadilan adalah sebesar 0.825. Contoh butir pernyataan dimensi keadilan adalah "Perusahaan sangat mempertimbangkan kebutuhan saya."

Semakin tinggi skor yang diperoleh partisipan dalam dimensi dukungan atasan menunjukkan bahwa partisipan merasakan semakin tingginya rasa kepedulian atasan dan perusahaan terhadap partisipan. Dimensi ini terdiri dari 12 butir pernyataan dan setelah dilakukan hasil uji analisis butir, ada 1 butir yang gugur karena nilai r (Corrected item to total correlation) dibawah 0,2 yaitu butir nomor 26. Oleh karena itu dimensi dukungan atasan menjadi berjumlah 11 butir. Nilai Alpha Cronbach yang diperoleh untuk dimensi dukungan atasan adalah sebesar 0.842. Contoh butir pernyataan dimensi dukungan atasan adalah "Perusahaan menghargai kontribusi saya". 
Semakin tinggi skor yang diperoleh partisipan dalam dimensi penghargaan organisasi menunjukkan bahwa partisipan merasakan semakin tingginya penghargaan yang diberikan perusahaan terhadap partisipan. Dimensi ini terdiri dari 12 butir pernyataan dan setelah dilakukan hasil uji analisis butir, tidak ada butir yang gugur karena seluruh nilai $\mathrm{r}$ (Corrected item to total correlation) diatas 0,2 . Oleh karena itu dimensi penghargaan organisasi tetap berjumlah 12 butir. Nilai Alpha Cronbach yang diperoleh untuk dimensi penghargaan organisasi adalah sebesar 0.823 . Contoh butir pernyataan dimensi penghargaan organisasi adalah "Jika perusahaan bisa mempekerjakan seseorang untuk menggantikan saya dengan gaji rendah maka perusahaan akan melakukannya."

\section{Skala Modal Psikologis}

Alat ukur yang digunakan adalah Psychological Capital Questionnaire (PCQ) yang dibuat oleh Luthans et al. (2007). PCQ terdiri dari 24 butir yang terbagi menjadi empat bagian, masingmasing bagian mewakili empat dimensi modal psikologis dan setiap dimensinya memiliki enam butir pernyataan.

Alat ukur ini sudah diadaptasikan di Indonesia dan dikembangkan oleh Bagian Riset dan Pengukuran Fakultas Psikologi Universitas Tarumanagara pada tahun 2013. Skala respon yang digunakan pada alat ukur ini adalah Skala Likert dengan penjelasan sebagai berikut, 1 = Sangat tidak sesuai; 2 = Tidak sesuai; 3 = Agak tidak sesuai; 4 = Agak sesuai; 5 = Sesuai; $6=$ Sangat Sesuai.

Semakin tinggi skor dimensi hope, maka semakin mampu individu dalam mencari jalan keluar dari permasalahan yang sedang dihadapinya. Selain itu, individu akan memiliki cita-cita atau tujuan hidup yang baik/positif sehingga membuatnya lebih bersemangat dalam menyelesaikan setiap pekerjaannya. Ketika diharuskan menghadapi suatu permasalahan ataupun terjadi hal buruk pada diri individu tersebut, hal-hal tersebut tidak akan membuat individu menjadi putus asa tapi akan membuat individu menjadi lebih bersemangat dalam menjalani hidupnya. Setelah dilakukan hasil uji analisis butir, tidak ada butir yang gugur karena nilai $\mathrm{r}$ (Corrected item to total correlation) diatas 0,2. Oleh karena itu dimensi hope tetap berjumlah 6 butir. Nilai Alpha Cronbach yang diperoleh untuk dimensi hope adalah sebesar 0.700. Contoh butir pernyataan dimensi hope adalah "Saat ini, saya bersemangat untuk mencapai target pekerjaan saya."

Selanjutnya semakin tinggi skor dimensi optimism, maka semakin individu melihat sisi positif dari permasalahan yang sedang dihadapinya di dalam pekerjaan. Selain itu, individu akan lebih memiliki rasa optimisme yang lebih tinggi walaupun terdapat hal buruk yang sedang terjadi kepada dirinya. Setelah dilakukan hasil uji analisis butir, ada 2 butir yang gugur karena nilai $r$ (Corrected item to total correlation) dibawah 0,2 yaitu butir nomor 20 dan 23. Oleh karena itu dimensi optimism menjadi berjumlah empat butir. Nilai Alpha Cronbach yang diperoleh untuk dimensi optimism adalah sebesar 0.715 . Contoh butir pernyataan dimensi optimism adalah "Jika saya harus menghadapi situasi yang buruk, saya percaya bahwa segala sesuatu akan berubah menjadi lebih baik."

Skor tinggi pada dimensi resilience, maka semakin individu dapat menghadapi setiap tantangan yang ada di dalam pekerjaannya. Selain itu, individu akan mampu dalam menyelesaikan setiap permasalahan yang sedang dihadapinya. Walaupun banyak hal buruk atau permasalahan yang harus dihadapinya, individu tidak akan mudah untuk menjadi stres dan akan mampu untuk menanggulanginya satu per satu. Setelah dilakukan hasil uji analisis butir, ada 1 butir yang gugur 
karena nilai $\mathrm{r}$ (Corrected item to total correlation) dibawah 0,2 yaitu butir nomor 13 . Oleh karena itu dimensi resilience menjadi berjumlah lima butir. Nilai Alpha Cronbach yang diperoleh untuk dimensi resilience adalah sebesar 0.782. Contoh butir pernyataan dimensi resilience adalah "Walaupun pekerjaan saya gagal, saya akan berusaha untuk memperbaikinya supaya dapat berhasil."

Skor tinggi dimensi self-efficacy mengartikan semakin tinggi rasa percaya diri yang dimiliki oleh individu untuk menyelesaikan target pekerjaannya. Individu yang memiliki skor tinggi pada dimensi ini akan merasa percaya diri ketika melakukan diskusi di dalam tim serta mampu untuk memberikan kontribusi dalam menyiapkan target tim. Setelah dilakukan hasil uji analisis butir pada dimensi self-efficacy, tidak ada butir yang gugur karena nilai $\mathrm{r}$ (Corrected item to total correlation) diatas 0,2. Oleh karena itu dimensi self-efficacy tetap berjumlah 6 butir. Nilai Alpha Cronbach yang diperoleh untuk dimensi self-efficacy adalah sebesar 0.867. Contoh butir pernyataan dimensi self-efficacy adalah Saya merasa percaya diri bahwa saya dapat menyelesaikan target pekerjaan saya."

\section{HASIL DAN PEMBAHASAN}

Sebelum melakukan uji hipotesis, peneliti melakukan uji normalitas untuk melihat normalitas penyebaran data. Uji normalitas adalah uji yang dilakukan untuk melihat kemungkinan variabel pengganggu atau residual memiliki distribusi normal. Berdasarkan data yang diperoleh, uji normalitas dalam penelitian ini dilakukan terhadap tiga variabel penelitian menggunakan one sample kolmogorov smirnov. Apabila nilai signifikansi data $\mathrm{p}>0.05$ maka distribusi data dikatakan normal.

Tabel 1. Hasil Uji Normalitas Variabel Psychological Ownership, Dukungan Organisasi dan Modal Psikologis

\begin{tabular}{lll}
\hline Variabel & Nilai Z & Signifikansi (p) \\
\hline Psychological Ownership & 1.221 & .101 \\
Dukungan Organisasi & 0.880 & .421 \\
Modal Psikologis & 0.400 & .997 \\
\hline
\end{tabular}

Pada variabel Psychological Ownership, nilai $\mathrm{Z}=1.221$ dan $\mathrm{p}=.101>0.05$ artinya data terdistribusi normal. Pada variabel Dukungan Organisasi, nilai $\mathrm{Z}=0.880$ dan $\mathrm{p}=.421>0.05$ artinya data terdistribusi normal. Pada variabel Modal Psikologis nilai $\mathrm{Z}=0.400$ dan $\mathrm{p}=.997>$ 0.05 artinya data terdistribusi normal. Selanjutnya uji coba hipotesis dilakukan dengan perhitungan regresi linear sederhana.

Berdasarkan analisa yang dilakukan, diperoleh nilai koefisien determinasi $R^{2}=0.278$. Hal ini menunjukan bahwa dukungan organisasi memberikan sumbangan sebesar $28 \%$ terhadap psychological ownership. Selanjutnya, dari perhitungan nilai regresi, diperoleh $\mathrm{F}=7.940, \mathrm{p}<0.05$, hal ini menunjukan bahwa hipotesis null ditolak, dengan demikian dapat dinyatakan bahwa dukungan organisasi memiliki peran terhadap psychological ownership.

Untuk mengetahui dimensi apa saja dari dukungan organisasi yang berperan terhadap psychological ownership, maka peneliti melakukan analisa tambahan. 
Tabel 2. Peran Dimensi Dukungan Organisasi terhadap Psychological Ownership

\begin{tabular}{lll}
\hline Dimensi & Skor T & Signifikansi \\
\hline Keadilan & -.960 & 0.341 \\
Dukungan Atasan & 1.560 & 0.124 \\
Penghargaan Organisasi & 2.318 & 0.024 \\
\hline
\end{tabular}

Dari hasil data di Tabel 2, nilai siginifikansi dimensi keadilan dan dukungan atasan lebih besar dari 0.05 sehingga kedua dimensi tersebut tidak berperan secara signifikan terhadap psychological ownership. Namun untuk dimensi penghargaan organisasi nilai signifikansinya dibawah 0.05, hal ini menunjukkan bahwa dimensi penghargaan organisasi memiliki peran yang signifikan terhadap psychological ownership.

Menunjukkan nilai koefisien determinasi $\mathrm{R}^{2}=0.342$ peran modal psikologis $34.2 \%$ terhadap psychological ownership. Selanjutnya, dari perhitungan nilai regresi, diperoleh $\mathrm{F}=7.933, \mathrm{p}<0.05$, hal ini menunjukan bahwa hipotesis nul ditolak, maka modal psikologis memiliki peran terhadap psychological ownership.

Untuk mengetahui dimensi apa saja dari modal psikologis yang berperan terhadap psychological ownership, maka peneliti melakukan analisa tambahan,

Tabel 3. Peran Dimensi Modal Psikologis terhadap Psychological Ownership

\begin{tabular}{lll} 
Dimensi & Skor T & Signifikansi \\
\hline Self-efficacy & 1.350 & 0.182 \\
Hope & -1.037 & 0.304 \\
Resilience & 3.496 & 0.001 \\
Optimism & .872 & 0.387 \\
\hline
\end{tabular}

Dari Tabel 3 menunjukkan untuk dimensi self-efficacy, hope dan optimism, nilai signifikansinya lebih besar dari 0.05 sehingga ketiga dimensi tersebut tidak berperan secara signifikan terhadap psychological ownership. Namun untuk dimensi resilience, nilai signifikansinya dibawah 0.05 , hal ini menunjukkan bahwa dimensi resilience memiliki peran yang signifikan terhadap psychological ownership. Hal ini dapat disimpulkan bahwa rendahnya kemampuan seseorang dalam menghadapi masalah dapat memengaruhi rendahnya nilai psychological ownership karyawan di dalam perusahaan.

Uji regresi untuk melihat peran dukungan organisasi dan modal psikologis terhadap psychological ownership secara bersamaan menunjukkan nilai koefisien determinasi $\mathrm{R}^{2}=0.340$ $(\mathrm{F}=16.246, \mathrm{p}<0.05)$. Hal ini menunjukan bahwa dukungan organisasi dan modal psikologis 
memberikan sumbangan sebesar $34 \%$ terhadap psychological ownership. Dari hasil ini menunjukan bahwa hipotesis II diterima, penelitian ini membuktikan bahwa dukungan organisasi dan modal psikologis memiliki peran terhadap psychological ownership.

Berdasarkan hasil penelitian terbukti bahwa dukungan organisasi memiliki peran yang signifikan terhadap psychological ownership. Hal ini memperkuat hasil penelitian yang dilakukan oleh Otken (2015) yang menyebutkan bahwa dukungan organisasi memiliki hubungan yang positif dengan psychological ownership. Oleh karena itu pemenuhan kebutuhan yang diterima karyawan dari perusahaan dapat menciptakan rasa memiliki yang tinggi karyawan terhadap perusahaan, melingkupi rasa penyatuan diri mereka terhadap perusahaan dan status peran di perusahaan menjadi identitas sosial mereka.

Jika dilihat lebih dalam lagi ke setiap dimensinya, hanya dimensi penghargaan organisasi yang memiliki peran secara signifikan terhadap psychological ownership. Dari penelitian yang dilakukan oleh Chi dan Han (dalam Ahmed, 2014) menjelaskan bahwa perasaan memiliki akan berkembang pada saat individu memiliki fair justice perception di dalam pikiran mereka. Jadi ada hubungan positif antara organizational justice perceptions dan psychological ownership (Ahmed, 2014). Hal ini bertentangan dari hasil penelitian ini, yaitu dimensi keadilan tidak berperan secara signifikan terhadap psychological ownership. Jadi dapat dikatakan bahwa perilaku adil perusahaan dalam mendistribusikan sumber daya manusia yang ada tidak berperan terhadap tingkat psychological ownership karyawan di dalam perusahaan.

Dimensi penghargaan organisasi dapat berperan secara signifikan, kemungkinan terkait dengan kebutuhan dasar manusia yang seperti diutarakan oleh Maslow (1943) mengenai teori motivasi. (Jerome, 2013). Dimensi penghargaan organisasi terlihat memenuhi kebutuhan manusia baik dari yang terendah sampai tertinggi, sehingga hal ini yang membuat karyawan mau untuk menginvestasikan dirinya kepada sebuah target, menurut Locke (dalam Pierce et al., 2002) setiap orang memiliki hasil kerja sendiri. Bagaimanapun, seseorang akan merasa memiliki yang dikerjakan, dibentuk dan dihasilkan sendiri. Melalui hasil pekerjaan sendiri, seseorang tidak hanya akan menginvestasikan waktu dan usaha fisik, namun juga energi psikis ke dalam hasil pekerjaannya. Benda atau sesuatu akan terlekat pada seseorang yang membuatnya karena benda tersebut adalah hasil seseorang yang mengusahakannya, sehingga seseorang yang membuat benda tersebut merasa memiliki, sama seperti seseorang merasa memiliki dirinya sendiri (Durkheim dalam Pierce et al., 2002). Usaha dan investasi dari diri seseorang pada suatu benda membuat seseorang merasa menjadi satu dengan benda tersebut dan membangun perasaan memiliki terhadap benda tersebut (Rochberg-Halton, 1980).

Berikutnya dari hasil penelitian juga didapatkan bahwa modal psikologis memiliki peranan yang signifikan terhadap psychological ownership, dengan kata lain bahwa karyawan yang memiliki kondisi positif psikologi yang tinggi memiliki peranan terhadap tingkat psychological ownership karyawan dalam bekerja. Hasil penelitian ini membantu memperkuat hasil penelitian sebelumnya yaitu self-efficacy oleh Gao (2000), self-efficacy oleh Gong, Huang dan Farh (2009) yang hanya mengaitkan salah dimensi modal psikologis terhadap psychological ownership. Namun apabila dilihat dari masing-masing dimensi modal psikologis dan dikaitkan dengan psychological ownership hanya dimensi resilience yang berperan secara signifikan terhadap psychological ownership. Jadi karyawan yang memiliki kemampuan untuk maju menghadapi permasalahan yang sedang dihadapinya mampu memiliki peranan yang signifikan terhadap psychological ownership. 
Hasil penelitian ini bertentangan dengan penelitian Arshad dan Abbasi (2014) yang menjelaskan bahwa dimensi hope berperan dalam memotivasi karyawan secara intrinsik dan menciptakan rasa keterlibatan dan keikutsertaan karyawan terhadap perusahaan, yang nantinya akan mengarahkan karyawan kepada rasa kepemilikan (sense of ownership) terhadap perusahaan. Dalam penelitian ini juga bertentangan dengan hasil penelitian yang dilakukan oleh Qiu, Hu, Zhang dan Li (2015) bahwa self-efficacy memiliki efek yang positif terhadap psychological ownership. Di dalam penelitian ini, dimensi self-efficacy tidak memiliki peranan yang siginifikan terhadap psychological ownership. Jadi dapat dikatakan bahwa peranan modal psikologis baru dapat memiliki peranan yang signifikan apabila dilihat secara utuh dan bukan secara parsial sehingga tidak dapat dikaitkan dengan masing-masing dimensinya. Namun perbedaan hasil penelitian ini bisa juga terkait dengan perbedaan latar belakang bidang pekerjaan yang dijalankan sehingga hasil yang diberikan berbeda.

Menurut pendapat peneliti, apabila dikaitkan dengan kondisi perusahaan PT. ABC, alasan dimensi resilience menjadi yang paling signfikan berperan terhadap psychological ownership dikarenakan kondisi perusahaan saat ini yang sedang menurun. Karyawan yang ada saat ini adalah karyawan yang mau tetap bertahan dan bangkit kembali bersama-sama dengan perusahaan sehingga dibutuhkan resilience yang tinggi dalam diri setiap karyawan di PT. ABC.

Dari hasil penelitian ini juga menunjukkan adanya peranan dukungan organisasi dan modal psikologis terhadap psychological ownership. Jadi kedua variabel bebas tersebut memiliki peranan yang signifikan terhadap psychological ownership. Hal ini menjelaskan bahwa tingkat psychological ownership mendapatkan pengaruh dari dukungan organisasi dan juga modal psikologis, sehingga tidak hanya faktor eksternal namun faktor internal juga memberikan dampak dan pengaruh. Terakhir, dari hasil penelitian ini nampaknya belum mewakili perusahaan yang bergerak di bidang retail, sebab untuk jawaban yang diberikan di perusahaan ini semuanya terlihat tinggi dan tercukupi. Berbeda dengan hasil wawancara dan observasi peneliti selama melakukan penelitian di PT. ABC. Selain itu jumlah responden dalam penelitian perlu lebih diperbanyak agar hasil yang ditampilkan dapat lebih baik dan terukur lagi.

\section{KESIMPULAN DAN SARAN}

\section{Kesimpulan}

Berdasarkan hasil analisis dapat disimpulkan bahwa psychological capital memiliki dampak yang lebih besar dibandingkan perceived organizational support. Dalam perceived organizational support, dimensi yang paling berperan terhadap psychological ownership adalah organizational reward, Sementara variabel psychological capital dimensi yang paling berperan adalah resilience. Di antara kedua variabel tersebut psychological capital lebih berperan terhadap psychological ownership.

\section{Saran}

Saran yang dapat diberikan untuk penelitian selanjutnya adalah penambahan jumlah partisipan penelitian agar diperoleh gambaran hubungan dukungan organisasi, modal psikologis dan psychological ownership yang lebih signifikan. Tambahan pula, disarankan juga supaya penelitian berikutnya dilakukan dengan setting yang berbeda. Di dalam penelitian ini hanya dilakukan di dalam satu perusahaan saja dan bergerak di bidang retail, untuk penelitian berikutnya mungkin dapat dilakukan terhadap bidang perusahaan yang lain. Hal ini dimaksudkan 
agar dapat memberikan gambaran dukungan organisasi, modal psikologis dan psychological ownership yang lebih lengkap pada lingkup organisasi yang ada.

Dalam melakukan penelitian berikutnya juga disarankan, agar tidak melakukan penelitian di tempat perusahaan sendiri. Hal ini dikarenakan apabila peneliti yang merupakan karyawan di perusahaan tersebut, maka partisipan yang notabene merupakan karyawan di perusahaan yang sama akan melakukan pengisian yang tidak mencerminkan kondisi sebenarnya. Jadi lebih baik penelitian dilakukan di perusahaan lain agar hasilnya lebih terpercaya.

Selain itu, untuk memperkaya kajian mengenai psychological ownership, maka penelitian selanjutnya disarankan untuk menambahkan topik lainnya yang dapat dihubungan dengan psychological ownership seperti psychological empowerment sebab dari penelitian ini terlihat bahwa faktor internal lebih berperan daripada faktor eksternal.

Dari hasil penelitian menunjukkan dukungan organisasi dan modal psikologis berperan terhadap psychological ownership, maka perusahaan perlu memperhatikan kebutuhan karyawan dalam bekerja sehingga pemenuhan kebutuhan sosial-emosional yang dapat berupa penghargaan dan persetujuan, sebagai bentuk pertalian (afiliasi) dan dukungan emosional dapat terpenuhi. Dari pemenuhan kebutuhan tersebut menciptakan rasa memiliki yang tinggi karyawan terhadap perusahaan, melingkupi rasa penyatuan diri mereka terhadap perusahaan dan status peran di perusahaan menjadi identitas sosial karyawan. Karyawan yang merasa mendapat perhatian dan penghargaan yang sesuai dari perusahaannya dapat lebih menunjukkan rasa kepemilikan dan tanggung jawab yang tinggi dalam bekerja.

Dilihat dari dimensi dukungan organisasi, yang paling signifikan berperan adalah dimensi penghargaan organisasi terhadap psychological ownership. Maka agar tingkat ownership karyawan di PT. ABC juga dapat semakin meningkat, perusahaan dapat memberikan pelatihanpelatihan terhadap karyawan yang dapat meningkatkan keterampilan, kemampuan dan pemenuhan kebutuhan sosial karyawan. Namun melihat kondisi perusahaan saat ini, maka pelatihan dapat diberikan secara internal dengan trainer internal sehingga tidak memerlukan biaya yang besar.

Melihat peran modal psikologis memiliki peranan terhadap psychological ownership, maka perusahaan harus terus memberikan pembekalan berupa soft skill untuk meningkatkan rasa percaya diri dan gambaran positif dalam setiap permasalahan yang sedang dihadapi. Perusahaan juga harus terus mensosialisasikan setiap nilai-nilai yang ada di dalam perusahaan agar semakin memperkuat nilai-nilai tersebut di dalam diri karyawan yang nantinya dapat membantu karyawan dalam bekerja.

Perusahaan perlu lebih memperhatikan proses rekrutmen yang ada, agar mampu menyeleksi karyawan yang sesuai dengan visi dan misi perusahaan serta memiliki karakter yang positif. Hal ini perlu dilakukan agar karyawan di dalam perusahaan mampu berhasil dalam menjalankan setiap tanggung jawab dan tugas yang diberikan kepadanya sehingga karyawan dapat memiliki kompetensi maupun karier yang baik di dalam perusahaan.

\section{REFERENSI}


Ahmed, H. T. (2014). Impact of organizational justice on affective commitment: Mediating role of psychological ownership and organizational identification. IOSR Journal of Business and Management, 16(1), 58-63.

Arshad, A. \& Abbasi, A. S. (2014). Spiritual leadership and psychological ownership: Mediating role of spiritual wellbeing. Science Internationale Lahore, 26 (3), 1265-1269.

Avey, J. B., Avolio, B. J., Crossley, C. R., \& Luthans, F. (2009). Psychological ownership: Theoretical extensions, measurement, and relation to work outcomes. Journal of Organizational Behavior, 30, 173-191

Beggan, J. K. (1992). On the social nature of nonsocial perceptions. The mere ownership effect. Journal of Personality and Social Psychology, 62(2), 229-237.

Belk, R. W. (1988). Possessions and the extended self. Journal of Consumer Research, 15, 139168.

Cockshaw, W. D., \& Shochet, I. (2010). The link between belongingness and depressive symptoms: An exploration in the workplace interpersonal context. Australian Psychologist, 45(4), 283-289.

Dirks, K. T., Cummings, L. L., \& Pierce, J. L. (1996). Psychological ownership in organizations: Conditions under which individuals promote and resist change. In R. W. Woodman \& W. A. Pasmore (Eds.), Research in Organizational Change and Development (9, pp.1-23). Greenwich, CT: JAI Press.

Dyne, V. L. \& Pierce, J. L. (2004). Psychological Ownership and Feelings of Possession: Three Field Studies Predicting Employee Attitudes and Organizational Citizenship Behavior. Journal of Organizational Behavior, 25(4), 439 - 459.

Eisenberger, R., Armeli, S., Rexwinkel, B., Lynch, P. D., \& Rhoades, L. (2001). Reciprocation of perceived organizational support. Journal of Applied Psychology, 86, $42-51$.

Eisenberger, R., Hungtington, R., Hutchison, S., \& Sowa, D. (1986). Perceived Organizational Support. Journal of Applied Psychology, 71, 500-507.

Eisenberger, R., Stinglhamber, F., Vandenberghe, C., Sucharski, I., \& Rhoades, L. (2002). Perceived supervisor support: Contributions to perceived organizational support and employee retention. Journal of Applied Psychology, 87, 565-573.

Furby, L. (1978a). Possessions: Toward a theory of their meaning and function throughout the life cycle. In P. B. Baltes (Ed.), Life Span Development and Behavior (1, pp. 297-336). New York: Academic Press.

(Gong, Y., Huang, J, C., \& Farh, J. L. (2009). Employee learning orientation, transformational leadership, and employee creativity: The mediating role of employee creative selfefficacy. Academy of Management Journal, 52, 765-778

Jafri, H. (2015). Increasing Employee Performance through Improved Sense of Ownership and Fulfillment of Expectations. An International Journal of Management Studies Vol. 5, No. 2, April - June

Jerome, N. (2013). Application of the Maslow's hierarchy of need theory; impacts and implications on organizational culture, human resource and employee's performance. International Journal of Business and Management Invention, 2(3), 39-45.

Lihardja, N. \& Rostiana. (2013). The influence of psychological capital to work engagement and organizational citizenship behavior. International Conference on Entrepreneurship and Business Management, 161-166. Jakarta: Universitas Tarumanagara.

Luthans, F., Avolio, B. J., Walumbwa, F. O., \& Li, W. (2005). The psychological capital of Chinese workers: Exploring the relationship with performance. Management and Organization Review, 1(2), 249-271. 
Luthans, F., Norman, S. M., Avolio, B. J., \& Avey, J. B. (2008). The mediating role of psychological capital in the supportive organizational climate-employee performance relationship. Journal of Organizational Behavior, 29(2), 219-238.

Luthans, F., Youssef, C. M., \& Avolio, B. J. (2007). Psychological capital: Developing the human competitive edge. NY: Oxford University Press.

Muljani, N. (2002). Kompensasi Sebagai Motivator Untuk Meningkatkan Kinerja Karyawan. Jurnal Manajemen \& Kewirausahaan Vol. 4(2), 108 - 122

Olckers, C. (2013). Psychological ownership: Development of an instrument. SA Journal of Industrial Psychology, 39(2), 1-13.

Olckers, C \& Plessis, Y. D. (2012). Psychological ownership: A managerial construct for talent retention and organisational effectiveness. African journal of business management, 6(7)

Otken, A. B. (2015). The relationship between perceived organizational support and psychological ownership, the role of organizational justice.

Pierce, J. L., \& Jussila, I. (2011). Psychological ownership and the organizational context: Theory, research, evidence and application. Cheltenham, UK: Edward Elgar.

Pierce, J. L., Jussila, I., \& Cummings, A. (2009). Psychological ownership within the job design context: Revision of the job characteristics model. Journal of Organizational Behavior, Vol. 6, 477-496.

Pierce, J. L., Kostova, T., \& Dirks, K. T. (2001). Toward a Theory of Psychological Ownership in Organizations. Academy of Management Review Vol. 26, No. 2: 298 - 310

Pierce, J. L., Kostova, T., \& Dirks, K. T. (2003). The state of psychological ownership: Integrating and extending a century of research. Review of General Psychology Journal.

Pierce, J. L., Kostova, T., Dirks, K. T., \& Olin, J. M. (2002). The state of psychological ownership: Integrating and extending a century of research. Review of General Psychology Journal, 7(1), November.

Poutsma, E., Eert, C. V., \& Ligthart, P. E. M. (2015). Employee Ownership and Organizational Citizenship Behavior: High Performance Ownership Systems and the Mediating Role of Psychological Ownership.

Qiu, M., Hu, B., Zhang, X., \& Li, Y. (2015). Employee's psychological ownership and selfefficacy as mediators between performance appraisal purpose and proactive behavior. Social Behavior and Personality, 43 (7), 1101 - 1110.

Rhoades, L, \& Eisenberger, R. (2002). Perceived organizational support: A review of the literature. Journal of Applied Psychology, 87, 698-714.

Rogers, L. \& Freundlich, F. (1998). Nothing measured, nothing gained. Employee Ownership Report, XVIII, No. 1. Oakland, CA: National Center for Employee Ownership. Retrieved October 20, 2009, from http://www.ownershipassociates.com

Simons, J. C., \& Buitendach, J. H. (2013). Psychological capital, work engagement and organisational commitment amongst call centre employees in South Africa. SA Journal of Industrial Psychology, 39(2), 1-12.

Wayne, S. J., Shore, L. M., \& Liden, R. C. (1997). Perceived organizational support and leadermember exchange: A social exchange perception. Academy of Management Journal, 40, $82-111$.

Youseff, C. M. \& Luthans, F. (2007). Positive organizational behavior in the workplace: the impact of hope, optimism, and resilience. Journal of Management, 33(5), 774-800. 